\title{
INFLUENCE OF AIRFLOW RATE AND FORWARD SPEED ON THE SPRAY DEPOSIT IN VINEYARDS
}

\author{
Emanuele Cerruto
}

\section{Introduction}

Airflow rate and forward speed are two among the most important parameters influencing the success of a pesticide application, as they deeply affect the environmental losses, the uniformity on the canopy, and the timeliness of intervention.

The benefits of air assistance for orchard spraying are known. The forced air jet transports the spray droplets throughout the target, moving the foliage to allow penetration and depositing the droplets on the plant surface, including the undersides of leaves.

Though, the choice of the correct amount of airflow rate is still investigated [1], as many are the variables to be considered: geometry of target plants (tree size, shape and foliage density, distance between row, training system), forward speed, type of fan unit (cross flow or axial flow).

Pergher and Gubiani [4] reported that, increasing the airflow rate from 7.0 to $8.6 \mathrm{~m}^{3} / \mathrm{s}$ in a hedgerow vineyard, leads to higher losses to the ground and lower deposition on the foliage. Pezzi and Rondelli [5] reported that in a Casarsa vineyard the spray losses doubled by increasing the fan speed from 1400 to $2500 \mathrm{rpm}$ and frequently these losses were not limited to the treatment area but drifted outside. Moreover, the high fan speed improved the degree and the uniformity of the spray coverage. Again, Cross et al. [3] showed that in young dwarf, dwarf and semi-dwarf apple trees, large reductions in airflow rate (from 11.3 to 7.5 to $4.1 \mathrm{~m}^{3} / \mathrm{s}$ ) can substantially reduce spray drift from axial fan sprayers, without affecting the variability of deposits on leaf surface. On the other hand, Salyani and Farooq [8] reported that airflow rate had a significant effect on spray penetration in citrus

Paper received 21.02.2006; accepted 01.06.2006

Prof. Ing. Emanuele Cerruto, Associate Professor (ecerruto@ unict.it), Dipartimento di Ingegneria Agraria, University of Catania, Italy.

Research developed within the 2001 MIUR project "Improvement of Deposition Efficiency of Vineyard Sprayers", prot. 2001073192. groves, but lower airflow rate gave comparable deposition to higher rates in most canopy location, so they concluded that lower airflow rate could reduce the fan energy requirements by up to $67 \%$.

Forward speed is another important factor that affects the real work capacity of the sprayers and the quality of the deposition. Planas et al. [6] showed that increasing sprayer speed (from $1.0 \mathrm{~m} / \mathrm{s}$ to $1.7 \mathrm{~m} / \mathrm{s}$ ) in apple grove, recovery was improved but uniformity was worse. Salyani and Withney [7] obtained similar results in citrus trees: increasing the forward speed increases also the variability on deposition into the crop.

The objective of this study is to analyse the influence of two airflow rates and three forward speeds on spray deposition from an air-assisted sprayer in a $\mathrm{Si}$ cilian hedgerow vineyard, taking into account also the development of the vegetation.

\section{Materials and methods}

\subsection{The vineyard}

The field tests were performed in a "cordone speronato" vineyard, cv "Nero d'Avola" with a layout of $2.50 \times 1.25 \mathrm{~m}$, in two phenological stages: "Beginning of berry touch" (code 77 of the BBCH scale, 12 June 2002), and "Beginning of ripening" (code 81 of the BBCH scale, 11 July 2002).

In the agricultural area of study (the South of Sicily), the hedgerow vineyard protection is realised by means of two/three dust sulphur applications (end of April and May), followed by two/three liquid applications (June-August). The standard machine is a towed sprayer, equipped with axial fan, arc-shaped spray boom, and turbulence nozzles. The volume application rates are some $650 \mathrm{~L} / \mathrm{ha}^{(\mathrm{a})}$.

The day before field tests, the main morphological quantities of the trees were measured: maximum and

\footnotetext{
(a) According to the 16th CGPM, 1979, Resolution 6, the symbol "L" for the unit litre has been adopted.
} 
minimum height of the vegetation, cordon height, depth of the vegetation, leaf area index (LAI).

In order to evaluate the distribution of the sprayed mixture on the canopy, each sample tree was divided into three equally spaced heights (Low, Middle, and High), and two depth zones (External of the sprayed side, and Internal of the sprayed side), as reported in Figure 1.

The mean LAI of each zone was calculated counting the number of leaves present on 24 trees and sampling a leaf every ten. The surface of the sampled leaves was measured in laboratory by means of an image analysis system made up of a digital videocamera (Pixera with 1.2 Mpixel, Pixera Corporation) and a measuring software (Image Pro Plus, Media Cybernetics). The computations were performed according to:

$$
L I_{i}=\frac{m_{i} \bar{S}}{a \times b}\left[m^{2} / m^{2}\right]
$$

where:

- $\mathrm{LAI}_{\mathrm{i}}$ : Leaf Area Index of the i-zone;

- $n_{\mathrm{i}}$ : number of total leaves present in the $\mathrm{i}$-zone;

- $\bar{S}_{\mathrm{i}}$ : mean area of the leaves present in the i-zone;

- a: row spacing;

- b: distance between two trees in the row direction.

These results were also used for the determination of the number of foliar layers as:

$$
\mathrm{nL}_{\mathrm{i}}=\frac{\mathrm{nS}}{\mathrm{b} \times \mathrm{Nh}}
$$

where:

- $\mathrm{nL}_{\mathrm{i}}$ : number of foliar layers of the $\mathrm{i}$-zone;

$-\Delta$ h: height of each zone.

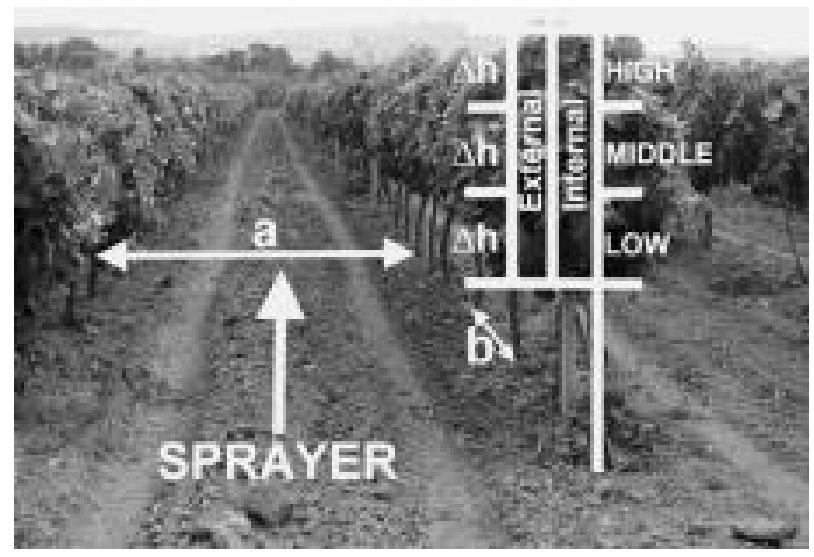

Fig. 1 - Schematic representation of the sampling zones.

\subsection{The sprayer}

The experimental tests were carried out using an air assisted towed sprayer (Agrimaster AT $1000 \mathrm{HF}$ Charlie, Figure 2), fitted with an axial fan (diameter = $0.80 \mathrm{~m}$, with two gear ratios: $3.5: 1$ and 4.4:1), 8 adjustable blades, 2 vertical spray booms equipped with 7 nozzles per side, and a main tank of $1000 \mathrm{~L}$. This choice is an innovation in the area of study, but a vertical spray boom for a hedgerow vineyard seems to be more appropriate than an arc-shaped one.

The airflow rate was measured on the basis of the CONAMA protocol [2], by means of a pipe (diameter $=1.0 \mathrm{~m}$ and length $=10 \mathrm{~m}$ ) fitted to the fan's intake. The air velocity inside the pipe was measured using a hot-wire anemometer (VelociCalc TSI Mod. 8355) at several regimes of the fan, so to establish a relationship between airflow rates and fan speeds.

The air velocity at the output was measured by means of the same anemometer, at three distances from the fan axis $(0.75 \mathrm{~m}, 1.25 \mathrm{~m}$ - equal to half the row spacing -, and $1.75 \mathrm{~m}$ ), every $0.20 \mathrm{~m}$ from 0.30 up to $2.10 \mathrm{~m}$ in height.

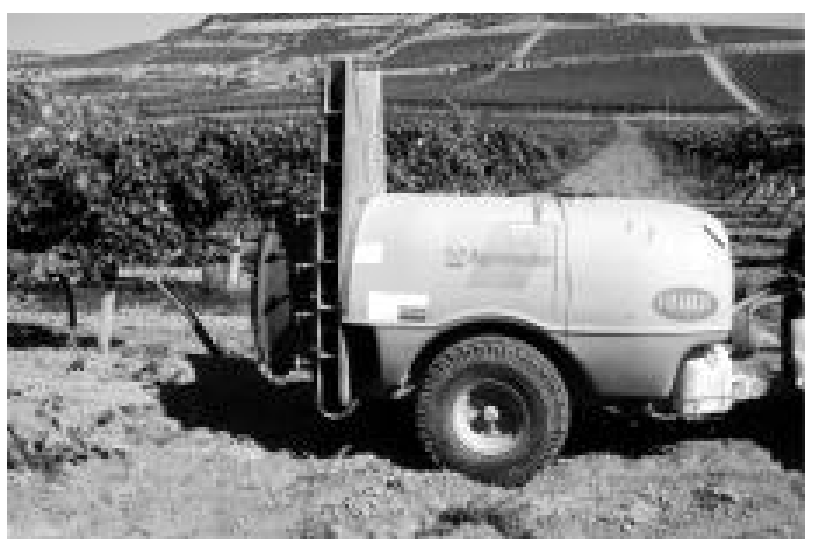

Fig. 2 - The sprayer used for the in field tests.

\subsection{The experimental tests}

In order to assess the influence of airflow rate and forward speed on the foliar deposition, a full factorial experimental design was adopted, with two airflow rates and three forward speeds.

The two selected airflow rates were $A_{2}=7.5 \mathrm{~m}^{3} / \mathrm{s}$ (the maximum delivered by the fan) and $A_{1}=3.9 \mathrm{~m}^{3} / \mathrm{s}$ (reduction of $48 \%$ ), while the three forward speeds were $\mathrm{v}_{1}=0.9 \mathrm{~m} / \mathrm{s}, \mathrm{v}_{2}=1.4 \mathrm{~m} / \mathrm{s}$, and $\mathrm{v}_{3}=2.8 \mathrm{~m} / \mathrm{s}$. To maintain the same pressure (1.2 $\mathrm{MPa}$ ) and comparable volume rates (some $350 \mathrm{~L} / \mathrm{ha}$ ), "Albuz ATR" nozzles with different orifice diameter were used: lilac $(0.8$ $\mathrm{mm})$, brown $(1.0 \mathrm{~mm})$, and orange $(1.5 \mathrm{~mm})$. Only 5 nozzles per side were switched on, pointed according to the vegetation shape. A summary of the experimental plan is reported in Table 1 .

\begin{tabular}{|c|c|c|c|c|}
\hline $\begin{array}{c}\text { Forward } \\
\text { speed, } \\
\mathrm{m} / \mathrm{s}\end{array}$ & $\begin{array}{c}\text { Nozzles } \\
\text { diameter, } \\
\mathrm{mm}\end{array}$ & $\begin{array}{c}\text { Flow } \\
\text { rate, } \\
\mathrm{L} / \mathrm{min}\end{array}$ & $\begin{array}{c}\text { Airflow } \\
\text { rate, } \\
\mathrm{m}^{3} / \mathrm{s}\end{array}$ & $\begin{array}{c}\text { Volume } \\
\text { rate, } \\
\mathrm{L} / \mathrm{ha}\end{array}$ \\
\hline $\mathrm{v}_{1}=0.9$ & 0.8 & 5.40 & $\mathrm{~A}_{1}=3.9$ & 384 \\
$\mathrm{v}_{2}=1.4$ & 1.0 & 7.12 & $\mathrm{~A}_{1}=3.9$ & 341 \\
$\mathrm{v}_{3}=2.8$ & 1.5 & 15.20 & $\mathrm{~A}_{1}=3.9$ & 363 \\
$\mathrm{v}_{1}=0.9$ & 0.8 & 5.40 & $\mathrm{~A}_{2}=7.5$ & 380 \\
$\mathrm{v}_{2}=1.4$ & 1.0 & 7.12 & $\mathrm{~A}_{2}=7.5$ & 327 \\
$\mathrm{v}_{3}=2.8$ & 1.5 & 15.20 & $\mathrm{~A}_{2}=7.5$ & 363 \\
\hline
\end{tabular}

TABLE 1 - Summary of the experimental tests. 
Applications were performed with just one spray pass for each replicate, after opening the nozzles on the right-hand side of the sprayer only. At the same time, temperature, air velocity and relative humidity were measured. A water solution with $2 \%$ of food dye Poinceau Red as a tracer and $0.05 \%$ of Agral as a surfactant was delivered.

The experimental design was arranged according to a randomised complete block design with four replicates, each replicate consisting in a piece of row about $30 \mathrm{~m}$ long.

\subsection{Leaves sampling and data analysis}

After spray application, 36 leaves were picked on each sample tree (6 randomly for each zone previously defined) and individually placed in plastic bags, suitably labelled. For the whole experiment, 864 leaves for each phenological stage were collected. Additionally 54 untreated leaves for each stage were also picked in order to assess the background deposit.

The foliar deposition was measured by means of a spectrophotometer (Jenway model, Jenway Ltd), according to the following procedure:

1. measure the surface $S_{1}\left[\mathrm{~cm}^{2}\right]$ of each sample leaf (using the image analysis system previously described);

2. wash each leaf with $\mathrm{V}_{\mathrm{c}}=50 \mathrm{~mL}$ of distilled water in order to extract the dye;

3. decant the washing solution in test tubes for at least $24 \mathrm{~h}$;

4. measure the absorbance $\mathrm{A}_{1}$ of about $5 \mathrm{~mL}$ of the decanted solution by means of the spectrophotometer. The wavelength was previously experimentally determined as that corresponding to the maximum absorption;

5. measure the absorbance $\mathrm{A}_{\mathrm{m}}$ of the mixture delivered in field;

6. calculate the volume of mixture deposited on the leaf as:

$$
\mathrm{v}_{1}=\frac{\mathrm{A}_{1}}{\mathrm{~A}_{\mathrm{m}}} \mathrm{V}_{\mathrm{r}} \times 1000[\mu \mathrm{L}]
$$

7. refer this volume to the overall leaf surface, so to calculate the unitary deposit as:

$$
\mathrm{d}_{\mathrm{i}}^{\prime}=\frac{\mathrm{v}_{\mathrm{i}}}{2 \cdot \mathrm{S}_{1}}\left|\mu \mathrm{L} / \mathrm{\textrm {cm } ^ { 2 }}\right|
$$

8. determine, in the same way, the average background unitary deposit $\mathrm{d}_{\mathrm{b}}$;

9. correct $\mathrm{d}_{1}^{\prime}$ according to the background deposit as:

$$
d_{1}=d_{i}^{\prime}-d_{h}
$$

10. normalise this deposit to a fixed volume rate $\mathrm{V}_{\mathrm{N}}$, so to account for the differences in the spray volume rates:

$$
\mathrm{d}_{\mathrm{e}}=\frac{\mathrm{V}_{\mathrm{N}}}{\mathrm{V}_{\mathrm{d}}} \mathrm{d}_{\mathrm{i}}
$$

where $\mathrm{V}_{\mathrm{d}}$ is the delivered volume rate. $\mathrm{V}_{\mathrm{N}}$ was arbitrarily fixed equal to $350 \mathrm{~L} / \mathrm{ha}$.
The normalised unitary deposits $d_{n}$ were statistically analysed applying the analysis of variance (ANOVA), separately for each stage. The ANOVA was carried out according to a split-plot design with two main plot factors (airflow rate and forward speed) and two sub-plot factors (height and depth of sampling). Mean separation was performed according to the Tukey's test, at $5 \%$ level of significance. In reporting average depositions, the normalised unitary deposits were weighted according to the average LAI of the sampling zone.

\section{Results and discussion}

\subsection{Morphological measures of the vineyard}

Figures 3 and 4 report the average geometric profile and the LAI distribution of the trees at the two growth stages (mean on 24 trees). They present only little differences, because of the training system and the pruning intervention. The overall LAI was 1.13 $\mathrm{m}^{2} / \mathrm{m}^{2}$ at stage 1 and $1.25 \mathrm{~m}^{2} / \mathrm{m}^{2}$ at stage 2 . Figure 5 , finally, reports the average number of foliar layers at the two stages.
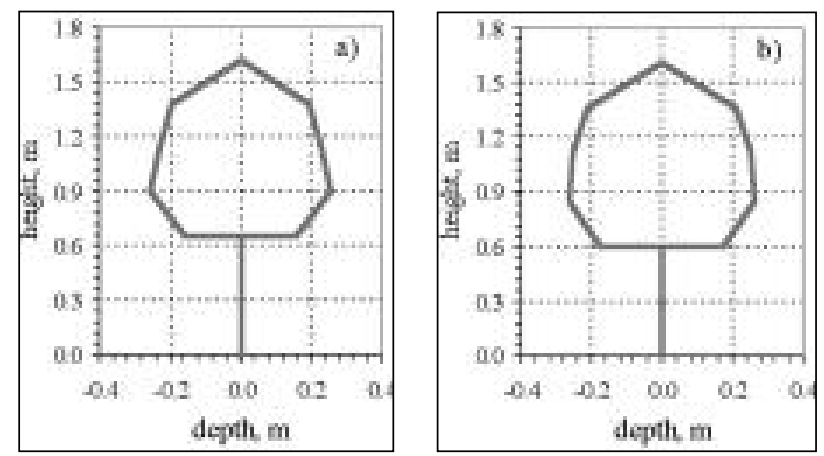

Fig. 3 - Average profile of the trees; a): stage 1; b): stage 2 .
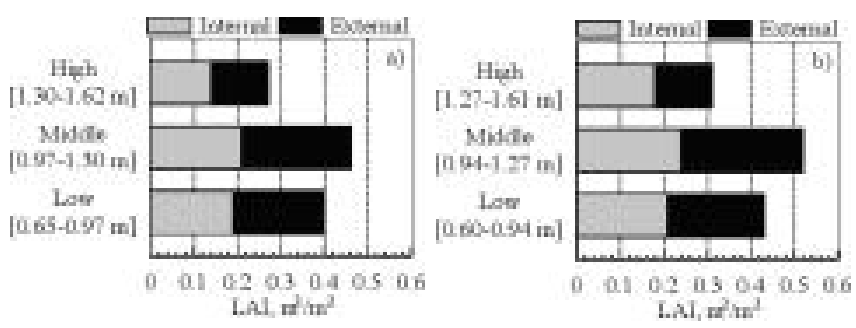

Fig. 4 - Average LAI of the trees; a): stage 1; b): stage 2.

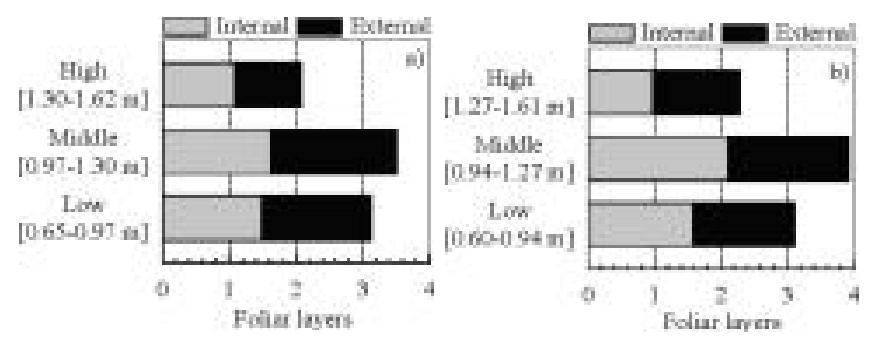

Fig. 5 - Average number of foliar layers of the trees; a): stage 1; b): stage 2 . 


\subsection{Measures on the sprayer}

The measured airflow rate showed a high linearity versus the fan speed (Figure 6); the coefficient of determination $\mathrm{R}^{2}(0.9977)$ was highly significant $(\mathrm{p}<0.001)$. The regression equation was used for fixing the fan speed, and then the power takeoff speed, in order to obtain the wished airflow rates.

Figure 7 reports the air velocity at the output, 1.25 $\mathrm{m}$ apart from the fan axis. Its average value in the range $0.50-1.70 \mathrm{~m}$, corresponding to the presence of vegetation, was $9.4 \mathrm{~m} / \mathrm{s}$ with an airflow rate of 3.9 $\mathrm{m}^{3} / \mathrm{s}$, and $18.2 \mathrm{~m} / \mathrm{s}$ with $7.5 \mathrm{~m}^{3} / \mathrm{s}$.

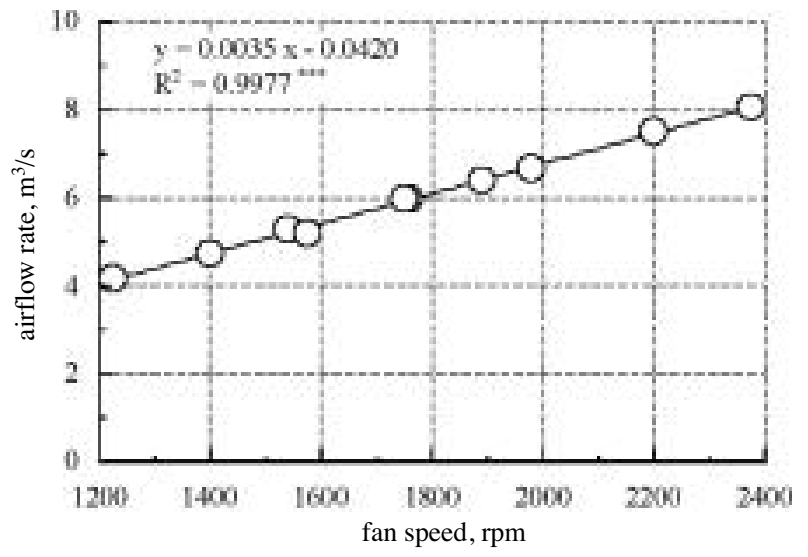

Fig. 6 - Airflow rate vs fan speed.

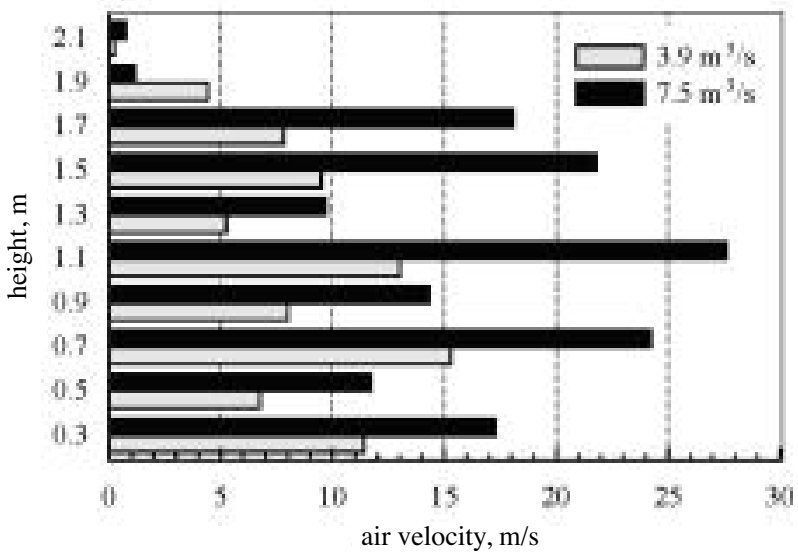

Fig. 7 - Air velocity at the output, $1.25 \mathrm{~m}$ apart from the fan axis.

\subsection{Foliar deposition - Stage 1}

Spray applications were performed between 9:05 and 9:35. Average air temperature was $28{ }^{\circ} \mathrm{C}(\mathrm{min}=$ $\left.26{ }^{\circ} \mathrm{C}, \max =30{ }^{\circ} \mathrm{C}\right)$, average HR $35 \%(\min =33 \%$, $\max =41 \%)$, and wind velocity negligible $(<0.2 \mathrm{~m} / \mathrm{s})$.

Raw data were transformed according to the power relation:

$$
\mathrm{d}_{\mathrm{t}}=\mathrm{d}_{\mathrm{n}}^{0.2}
$$

in order to normalise the frequency distribution (Figure 8 ) and equalise the variances. Table 2 reports the results of the ANOVA, applied to the transformed data. It shows that neither airflow rate, nor forward speed, nor their interaction, significantly influence the foliar deposition.

These first results suggest the opportunity to operate in field, if possible, at high forward speed (some $2.8 \mathrm{~m} / \mathrm{s})$ and low airflow rate $\left(\leq 3.9 \mathrm{~m}^{3} / \mathrm{s}\right)$. Increasing the forward speed, in fact, ensures a greater rapidity of intervention, while reducing the airflow rate results both in a little higher mean deposit $(0.364$ vs 0.310 $\mu \mathrm{L} / \mathrm{cm}^{2}, \mathrm{p}=0.051$ ) and a lower power consumption. Moreover, the mean variability is not influenced by the levels of airflow rate and forward speed. The overall coefficients of variation, in fact, assume comparable values for each condition (Table 3).

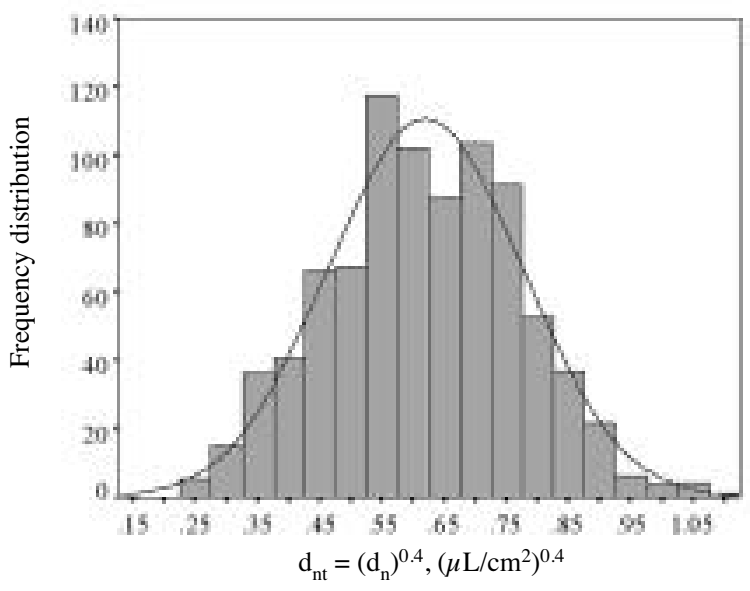

Fig. 8 - Frequency distribution of the transformed data.

\begin{tabular}{|c|c|c|c|c|c|}
\hline Source & SS & df & MS & $\mathrm{F}$ & p-level \\
\hline \multicolumn{6}{|c|}{ Main plot analysis } \\
\hline Replicate & 0.1863 & 3 & 0.0621 & 0.628 & $0.608^{\mathrm{ns}}$ \\
\hline Air (A) & 0.4473 & 1 & 0.4473 & 4.520 & $0.051^{\mathrm{ns}}$ \\
\hline Speed (S) & 0.1923 & 2 & 0.0961 & 0.972 & $0.401^{\mathrm{ns}}$ \\
\hline $\mathrm{A}_{-} \mathrm{S}$ & 0.0753 & 2 & 0.0376 & 0.380 & $0.690^{\mathrm{ns}}$ \\
\hline Error(1) & 1.4843 & 15 & 0.0990 & & \\
\hline \multicolumn{6}{|c|}{ Sub-plot analysis } \\
\hline Height $(\mathrm{H})$ & 0.8546 & 2 & 0.4273 & 11.074 & $0.000^{* * * *}$ \\
\hline Depth (D) & 2.8184 & 1 & 2.8184 & 73.044 & $0.000^{* * *}$ \\
\hline $\mathrm{H} \times \mathrm{D}$ & 0.3917 & 2 & 0.1958 & 5.076 & $0.008^{* *}$ \\
\hline $\mathrm{A} \times \mathrm{H}$ & 0.1197 & 2 & 0.0599 & 1.551 & $0.218^{\mathrm{ns}}$ \\
\hline$A \times D$ & 0.0092 & 1 & 0.0092 & 0.237 & $0.627^{\mathrm{ns}}$ \\
\hline $\mathrm{S} \times \mathrm{H}$ & 0.5682 & 4 & 0.1421 & 3.682 & $0.008^{* *}$ \\
\hline$S \times D$ & 0.0910 & 2 & 0.0455 & 1.179 & $0.312^{\mathrm{ns}}$ \\
\hline $\mathrm{A} \times \mathrm{H} \times \mathrm{D}$ & 0.0268 & 2 & 0.0134 & 0.347 & $0.708^{\mathrm{ns}}$ \\
\hline $\mathrm{S} \times \mathrm{H} \times \mathrm{D}$ & 0.2551 & 4 & 0.0638 & 1.653 & $0.168^{\mathrm{ns}}$ \\
\hline $\mathrm{A} \times \mathrm{S} \times \mathrm{H}$ & 0.5682 & 4 & 0.1420 & 3.681 & $0.008^{* *}$ \\
\hline $\mathrm{A} \times \mathrm{S} \times \mathrm{D}$ & 0.0936 & 2 & 0.0468 & 1.213 & $0.302^{\mathrm{ns}}$ \\
\hline $\mathrm{A} \times \mathrm{S} \times \mathrm{H} \times \mathrm{D}$ & 0.1576 & 4 & 0.0394 & 1.021 & $0.401^{\mathrm{ns}}$ \\
\hline Error(2) & 3.4727 & 90 & 0.0386 & & \\
\hline Sampling & 9.9951 & 720 & 0.0139 & & \\
\hline
\end{tabular}

$\mathrm{CV}(1)=51 \% ; \mathrm{CV}(2)=32 \% ; * * *$ : significant at $\mathrm{p}=0.1 \% ; * *$; significant at $\mathrm{p}=1 \%$; * significant at $\mathrm{p}=5 \%$; ns: not significant

TABLE 2 - Stage 1: ANOVA of the normalised deposit 


\begin{tabular}{|l|c|c|c|}
\hline Forward speed, m/s & 0.9 & 1.4 & 2.8 \\
\hline CV & $60 \%$ & $60 \%$ & $64 \%$ \\
\hline Airflow rate, $\mathrm{m}^{3} / \mathrm{s}$ & 3.9 & 7.5 \\
\hline CV & $60 \%$ & $62 \%$ \\
\hline
\end{tabular}

TABlE 3 - Stage 1: Coefficients of variation of the normalised deposit.

Significant differences exist between the two depths, as well as among the three heights. The mean deposit on the external layer $\left(0.403 \mu \mathrm{L} / \mathrm{cm}^{2}\right)$ is 1.51 times that present on the internal one $\left(0.266 \mu \mathrm{L} / \mathrm{cm}^{2}\right.$, Figure 9). The same proportion holds for each airflow rate (interaction air $\times$ depth not significant).

Figure 10 reports the average deposit on the three height zones: the deposit is significantly higher on the high zone of the canopy, probably because of the lowest LAI and number of foliar layers (Figures 4 and 5).

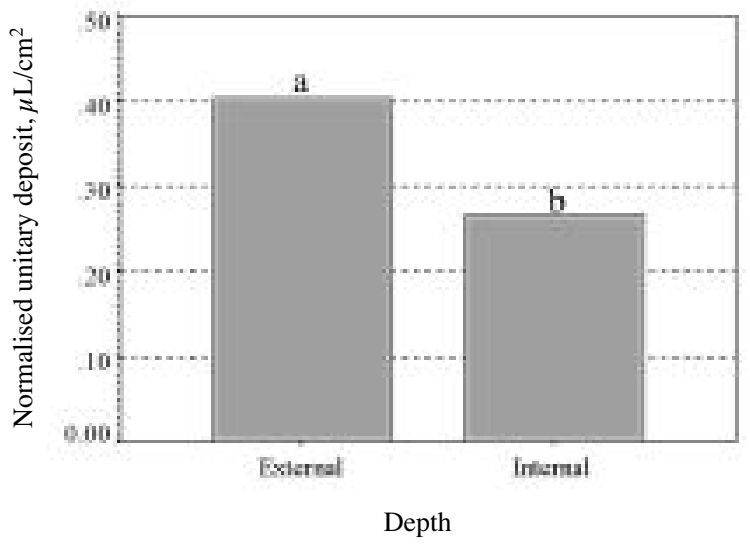

Fig. 9 - Stage 1: Normalised unitary deposit on the two depths. (Mean separation by Tukey's test at 5\% level).

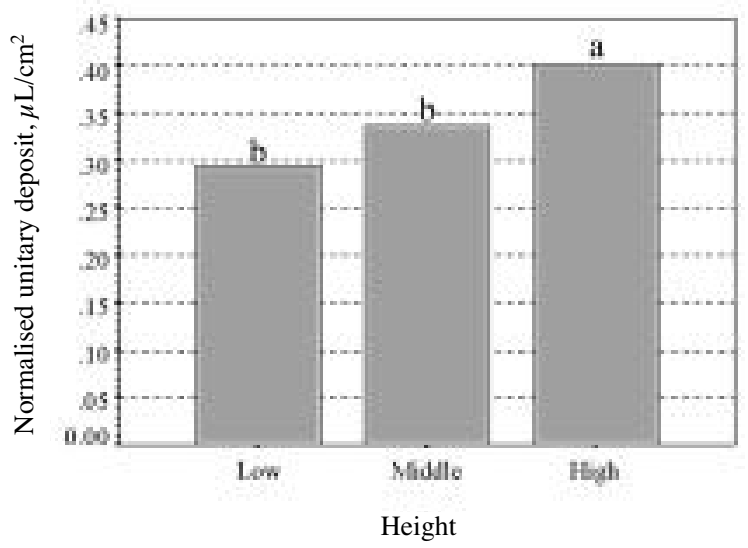

Fig. 10 - Stage 1: Normalised unitary deposit on the three heights. (Mean separation by Tukey's test at 5\% level).

This average result is influenced by depth and forward speed. Examining the interaction height $\times$ depth (Figure 11), emerges a greater reduction of deposit in the middle-internal zone, certainly because of the higher value of LAI and foliar layers. The height $\times$ speed interaction (Figure 12) shows a clear trend to an increase in the differences among the three heights when the forward speed is rising. This more in depth analysis suggest that forward speeds of some 1.4-1.7 $\mathrm{m} / \mathrm{s}$ could be more appropriate for treatments.

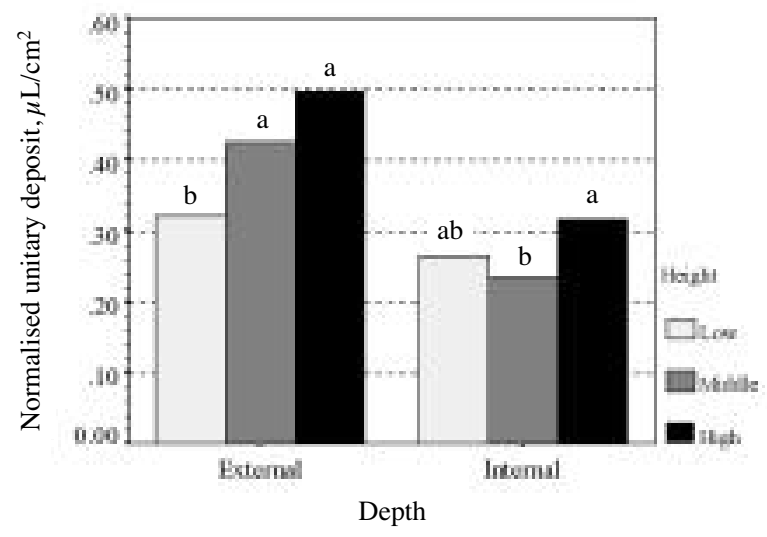

Fig. 11 - Stage 1: Normalised unitary deposit on the two depths. (Mean separation at each depth by Tukey's test at 5\% level).

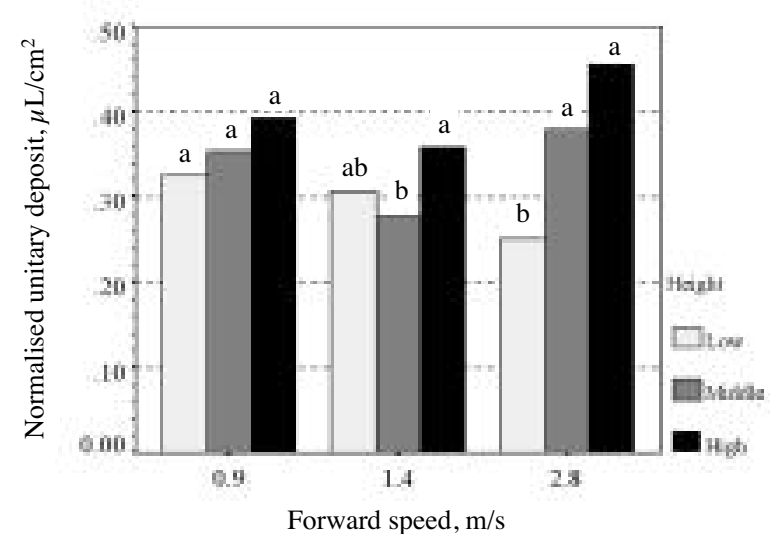

Fig. 12 - Stage 1: Normalised unitary deposit vs forward speed. (Mean separation at each forward speed by Tukey's test at 5\% level).

\subsection{Foliar deposition - Stage 2}

In the second stage spray applications were performed between 8:58 and 9:33. Average air temperature was $34{ }^{\circ} \mathrm{C}\left(\min =32{ }^{\circ} \mathrm{C}\right.$, $\left.\max =36{ }^{\circ} \mathrm{C}\right)$, average HR $28 \%(\min =24 \%, \max =32 \%)$, and wind velocity negligible $(<0.2 \mathrm{~m} / \mathrm{s})$.

Once again, the power transformation:

$$
\mathrm{d}_{\mathrm{u}}=\mathrm{d}_{\mathrm{n}}^{0.2}
$$

on the raw data was necessary to normalise the frequency distribution and equalise the variances.

Table 4 reports the results of the ANOVA, applied to the transformed data. The main plot analysis leads to the same conclusions drawn in the first experiment: in fact, airflow rate (Figure 13) and forward speed 
(Figure 14) do not significantly influence the mean foliar deposition. The overall mean deposit (grand mean) is however lower than that of the first stage $\left(0.301 \mu \mathrm{L} / \mathrm{cm}^{2}\right.$ vs $0.337 \mu \mathrm{L} / \mathrm{cm}^{2},-11 \%$, probably due to the $11 \%$ increase in the LAI). The greater LAI has also produced an increase in the variability: the coefficients of variation, in fact, are some $72 \%$ (Table 5), while they were some $62 \%$ in the first growth stage.

\begin{tabular}{|c|c|c|c|c|c|}
\hline Source & SS & df & MS & F & p-level \\
\hline \multicolumn{6}{|c|}{ Main plot analysis } \\
\hline Replicate & 0.2089 & 3 & 0.0696 & 0.252 & $0.858^{\mathrm{ns}}$ \\
\hline Air (A) & 0.0117 & 1 & 0.0117 & 0.042 & $0.839^{\mathrm{ns}}$ \\
\hline Speed (S) & 0.0886 & 2 & 0.0443 & 0.161 & $0.853^{\text {ns }}$ \\
\hline $\mathrm{A} \times \mathrm{S}$ & 1.3157 & 2 & 0.6578 & 2.385 & $0.126^{\mathrm{ns}}$ \\
\hline Error(1) & 4.1376 & 15 & 0.2758 & & \\
\hline \multicolumn{6}{|c|}{ Sub-plot analysis } \\
\hline Height $(\mathrm{H})$ & 2.2584 & 2 & 1.1292 & 39.385 & $0.000^{* * *}$ \\
\hline Depth (D) & 5.2332 & 1 & 5.2332 & 182.528 & $0.000^{* * *}$ \\
\hline $\mathrm{H} \times \mathrm{D}$ & 0.2764 & 2 & 0.1382 & 4.820 & $0.010^{*}$ \\
\hline $\mathrm{A} \times \mathrm{H}$ & 0.1556 & 2 & 0.0778 & 2.714 & $0.072^{\mathrm{ns}}$ \\
\hline$A \times D$ & 0.4333 & 1 & 0.4333 & 15.114 & $0.000^{* * *}$ \\
\hline $\mathrm{S} \times \mathrm{H}$ & 0.3449 & 4 & 0.0862 & 3.007 & $0.022^{*}$ \\
\hline $\mathrm{S} \times \mathrm{D}$ & 0.2079 & 2 & 0.1039 & 3.625 & $0.031^{*}$ \\
\hline $\mathrm{A} \times \mathrm{H} \times \mathrm{D}$ & 0.0011 & 2 & 0.0005 & 0.019 & $0.982^{\mathrm{ns}}$ \\
\hline $\mathrm{S} \times \mathrm{H} \times \mathrm{D}$ & 0.1016 & 4 & 0.0254 & 0.886 & $0.476^{\mathrm{ns}}$ \\
\hline $\mathrm{A} \times \mathrm{S} \times \mathrm{H}$ & 0.6409 & 4 & 0.1602 & 5.589 & $0.000^{* * *}$ \\
\hline $\mathrm{A} \times \mathrm{S} \times \mathrm{D}$ & 0.0945 & 2 & 0.0472 & 1.647 & $0.198^{\mathrm{ns}}$ \\
\hline $\mathrm{A} \times \mathrm{S} \times \mathrm{H} \times \mathrm{D}$ & 0.0873 & 4 & 0.0218 & 0.761 & $0.553^{\mathrm{ns}}$ \\
\hline Error(2) & 2.5803 & 90 & 0.0287 & & \\
\hline Sampling & 11.1402 & 720 & 0.0155 & & \\
\hline
\end{tabular}

TABLE 4 - Stage 2: ANOVA of the normalised deposit.

\begin{tabular}{|l|c|c|c|}
\hline Forward speed, $\mathrm{m} / \mathrm{s}$ & 0.9 & 1.4 & 2.8 \\
\hline CV & $71 \%$ & $71 \%$ & $73 \%$ \\
\hline Airflow rate, $\mathrm{m}^{3} / \mathrm{s}$ & 3.9 & 7.5 \\
\hline $\mathrm{CV}$ & $73 \%$ & $71 \%$ \\
\hline
\end{tabular}

TABLE 5 - Stage 2: Coefficients of variation of the normalised deposit.

The difference between external $\left(0.386 \mu \mathrm{L} / \mathrm{cm}^{2}\right)$ and internal layer $\left(0.215 \mu \mathrm{L} / \mathrm{cm}^{2}\right.$, ratio $\left.=1.80\right)$ becomes more evident: the greater LAI makes more difficult the penetration of the droplets inside the canopy. However, the interaction air $\times$ depth is statistically significant: Figure 15 shows that increasing the airflow rate results in a greater deposition on the inner part of the canopy. This result indicates the necessity of using not too low airflow rates at full foliage stage. Further experiments could help in understanding this aspect.

Foliar deposition is also influenced by forward

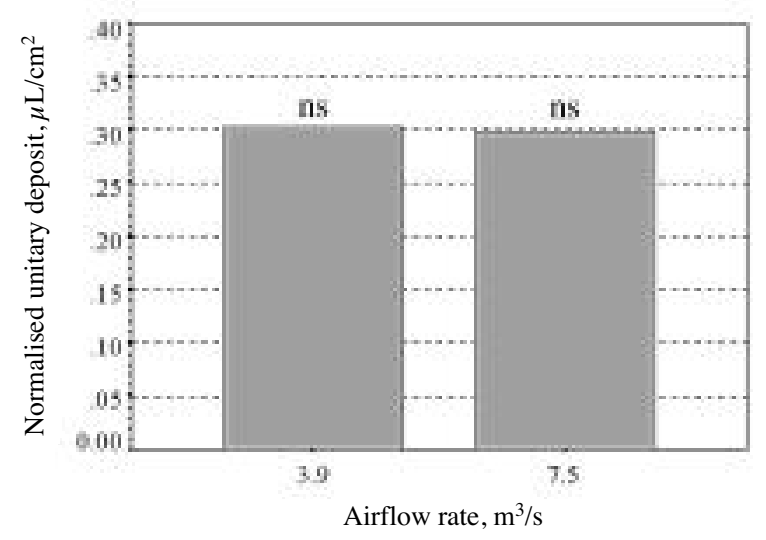

Fig. 13 - Stage 2: Normalised unitary deposit vs airflow rate. (ns: not significant).

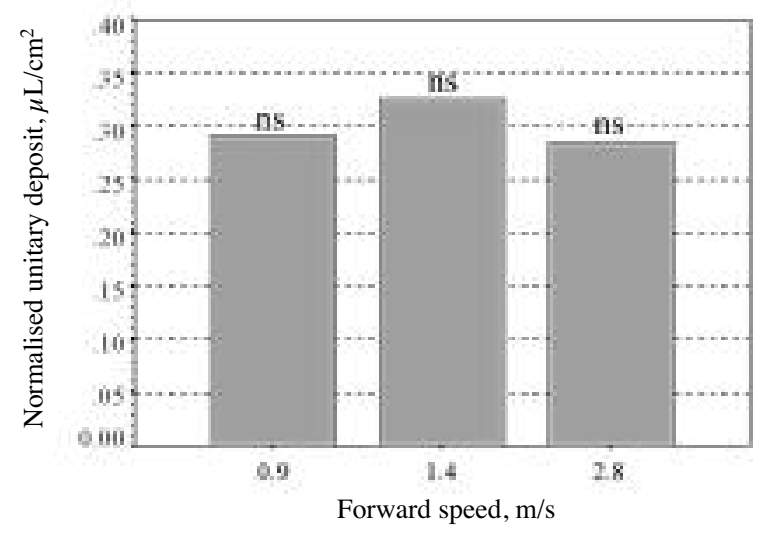

Fig. 14 - Stage 2: Normalised unitary deposit vs forward speed. (ns: not significant).

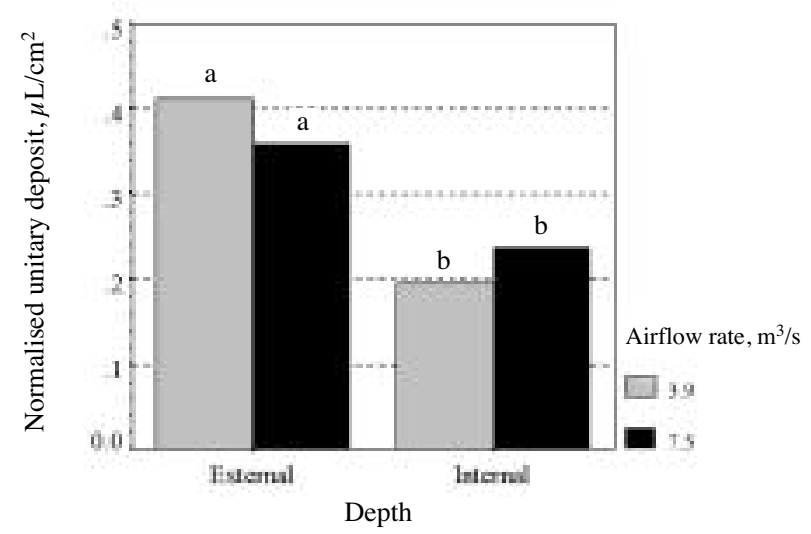

Fig. 15 - Stage 2: Normalised unitary deposit on the two depths. (Mean separation by Tukey's test at 5\% level).

speed along with depth (interaction speed $\times$ depth statistically significant at $\mathrm{p}=0.031)$. The interaction (Figure 16) shows a reduction of the deposit in the inner part of the canopy equal to $37 \%$ with $0.9 \mathrm{~m} / \mathrm{s}$, $42 \%$ with $1.4 \mathrm{~m} / \mathrm{s}$, and $54 \%$ with $2.8 \mathrm{~m} / \mathrm{s}$. These results confirm the opportunity to operate in field at $1.4-1.7 \mathrm{~m} / \mathrm{s}$.

The same conclusion can be drawn analysing the speed $\times$ height interaction (Figure 17): the highest and the most uniform foliar deposition can be obtained with the intermediate forward speed $(1.4 \mathrm{~m} / \mathrm{s})$. 


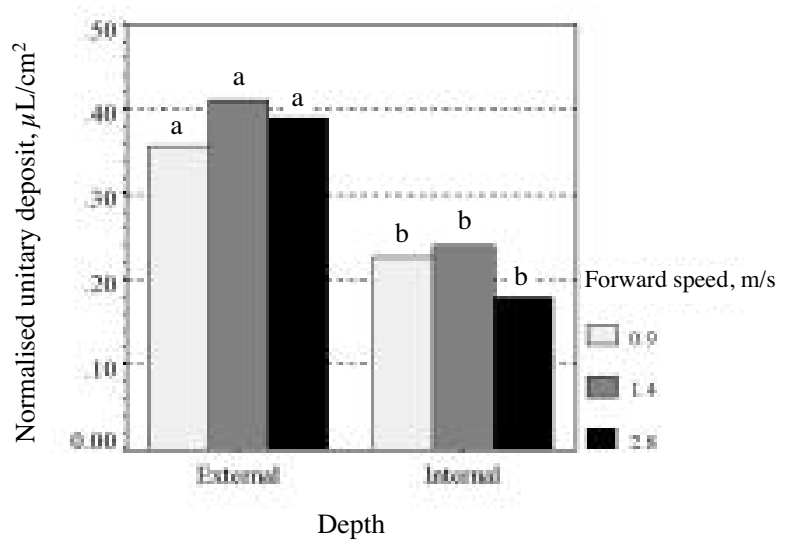

Fig. 16 - Stage 2: Normalised unitary deposit on the two depths. (Mean separation by Tukey's test at 5\% level).

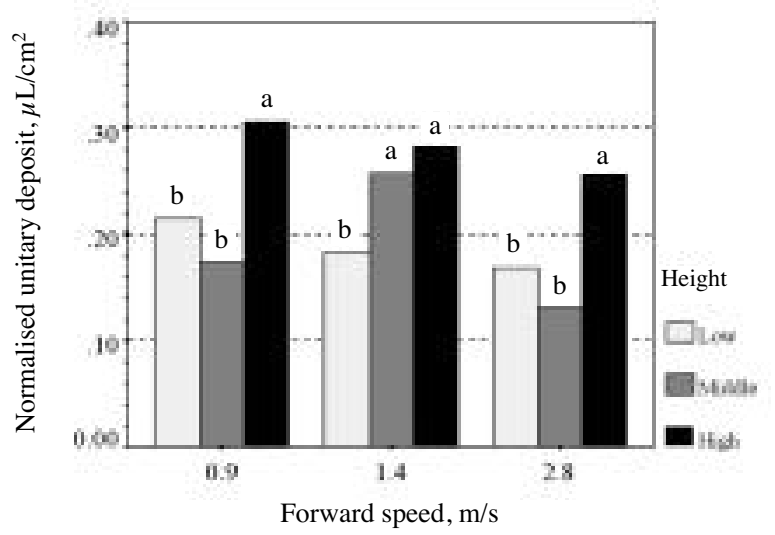

Fig. 17 - Stage 2: Normalised unitary deposit vs forward speed. (Mean separation at each forward speed by Tukey's test at 5\% level).

\section{Conclusions}

These results allow drawing the following conclusions about airflow rate and forward speed:

- airflow rates in the range $3.9-7.5 \mathrm{~m}^{3} / \mathrm{s}$ do not significantly influence the mean foliar deposition in both the two growth stages;

- only in the second growth stage (full foliage development), increasing the airflow rate leads to an improvement of the foliar deposition on the inside part of the canopy;

- forward speeds in the range $0.9-2.8 \mathrm{~m} / \mathrm{s}$ do not significantly influence the mean foliar deposition in both the two growth stages;

- the overall variability (CVs) is the same for each airflow rate and forward speed, but the intermediate forward speed $(1.4 \mathrm{~m} / \mathrm{s})$ gives the best uniformity on the canopy;

- further experimental tests are necessary to better assess the influence of the airflow rate.

\section{Acknowledgements}

The Author acknowledges Dr. Giuseppe Emma and Dr. Giuseppe Tornello for their valuable help during the experimental tests.

\section{References}

[1] Balsari P., Tamagnone M., The Necessity to Determine the Correct Amount of Air to Use in Airblast Sprayer, Proceedings on CD-ROM of the AGENG98, 24-27 August 1998, Oslo.

[2] Conama, Protocolli per il rilievo delle caratteristiche funzionali e della sicurezza delle macchine agricole, 1996.

[3] Cross J.V., Walklate P.J., Murray R.A., RichardSON G.M. Spray Deposits and Losses in Different Sized Apple Trees from an Axial Fan Orchard Sprayer: 3. Effects of Air Volumetric Flow Rate, Crop Protection, 22 (2003), 381-394.

[4] Pergher G., Gubiani R., The Effect of Spray Application Rate and Airflow Rate on Foliar Deposition in a Hedgerow Vineyard, Journal of Agricultural Engineering Research, (1995) 61, 205-216.

[5] Pezzi F., Rondelli V., The Performance of an Air-assisted Sprayer operating in Vines, Journal of Agricultural Engineering Research, (2000) 76, 331-340.

[6] Planas S., Solanelles F., Fillat A., Walklate P., Miralles A., Ade G., Pezzi F., Val L., Andersen P.G., Advances on Air-Assisted Spraying on the Mediterranean Orchards (Fruit, Vine and Citrus), Proceedings on CDROM of the AGENG98, 24-27 August 1998, Oslo.

[7] Salyani M., Withney J.D., Ground Speed Effect on Spray Deposition Inside Citrus Trees, Transactions of the ASAE 33 (2), March-April, 1990, 361-366.

[8] Salyani M., FarooQ M., Effect of Sprayer Airflow on Spray Movement within Tree Canopy, Proceedings of the VII Workshop on Spray Application Techniques in Fruit Growing, 25-27 June 2003, Cuneo, Italy, 227-235.

\section{SUMMARY}

The present paper reports the results of some spray application trials carried out in a hedgerow vineyard to assess the influence of airflow rate and forward speed on the foliar deposition, keeping approximately constant the volume application rate. The experimental tests were carried out using an air assisted towed sprayer, fitted with an axial fan and two spray booms equipped with seven turbulence nozzles.

A full factorial experimental design with two air flow rates ( 3.9 and $7.5 \mathrm{~m}^{3} / \mathrm{s}$ ) and three forward speeds $(0.9,1.4$, and $2.8 \mathrm{~m} / \mathrm{s})$ was adopted, arranged according to a randomised complete block design with four replicates. To take into account the development of the vegetation, the experimental plan was replicated in two phenological stages: "Beginning of berry touch" and "Beginning of ripening".

After spray application (just one spray pass for each replicate, delivering a water solution with a food dye as a tracer and a surfactant), 36 leaves were picked on each sample tree, equally shared among three heights and two depths. The foliar deposition was measured by means of a spectrophotometer.

The main results show that neither airflow rate, nor forward speed, significantly influence the average foliar deposition in both phenological stages. The overall variability (coefficients of variation) is also almost 
constant. However, in the second stage, the greater airflow rate improves the foliar deposition on the inside part of the canopy, suggesting the necessity of using not too low air flow rates at full foliage development. Also the forward speed interacts with the sampling zones, showing that at $2.8 \mathrm{~m} / \mathrm{s}$ the differences among the three heights and the two depths increase, thus suggesting the opportunity to operate in field at $1.4-1.7 \mathrm{~m} / \mathrm{s}$.

Key words:

Sprayer, Crop protection, Colorimetric analysis. 